\title{
The Policy Argument for Healthcare Workforce Diversity
}

\author{
Michael O. Mensah, B.A. ${ }^{7}$ and Benjamin D. Sommers, M.D., Ph.D. ${ }^{2}$ \\ 'Department of Health Policy \& Management, Harvard School of Public Health / University of California, San Francisco, Boston, MA, USA; ${ }^{2}$ Harvard \\ School of Public Health / Brigham \& Women's Hospital, Boston, MA, USA.
}

This perspectives article considers the potential implications an affirmative action ban would have on patient care in the US. A physician's race and ethnicity are among the strongest predictors of specialty choice and whether or not a physician cares for Medicaid and uninsured populations. Taking this into account, research suggests that an affirmative action ban in university admissions would sharply reduce the supply of primary care physicians to Medicaid and uninsured populations over the coming decade. Our article compares current conditions to the potential effect of an affirmative action ban by projecting how many future medical students will become primary care physicians for Medicaid and uninsured patients by 2025 . Based on previous evidence and current medical student training patterns, we project that a ban could deny primary care access for 1.25 million of our nation's most vulnerable patients, considerably worsening existing healthcare disparities. More broadly, we argue that the effects of eliminating affirmative action would be fundamentally contrary to the Association of American Medical Colleges' stated goal of medical education- "to improve the health of all."

KEY WORDS: affirmative action; medical school admissions; underserved care; primary care; health disparities.

J Gen Intern Med 31(11): 1369-72

DOI: $10.1007 /$ s11606-016-3784-1

(c) Society of General Internal Medicine 2016

$\mathrm{O}$ n December 9, 2015, the US Supreme Court heard oral arguments in Fisher v. University of Texas at Austin, a case concerning affirmative action in higher education. By a narrow 4-3 ruling announced in June 2016, the Court upheld the right of universities to use affirmative action in their admissions decisions. However, the debate over affirmative action will likely continue at the state and federal level over the coming years. A broad ban on affirmative action would prohibit medical schools from considering race in admissions decisions. Meanwhile, policymakers continue to be concerned about a possible shortage of primary care physicians (PCPs), with one estimate from the Association of American Medical Colleges (AAMC) projecting a shortage of 31,000 by 2025 , though this number is itself the subject of considerable debate. ${ }^{1}$ Less controversial than

Received February 29, 2016

Revised June 3, 2016

Accepted June 9, 2016

Published online July 18, 2016 whether there is a shortage of PCPs - and the size of that shortage - is the geographic maldistribution of primary care physicians nationally and disparities in physicians' willingness to care for patients with Medicaid and without any insurance compared to other types of coverage. ${ }^{2}$ All told, the federal government estimates that more than 60 million Americans live in primary care health professional shortage areas (HPSAs). ${ }^{3}$ Without more PCPs willing to care for these populations, many Americans will continue to have limited access to primary care.

Research shows that a physician's race and ethnicity are among the strongest predictors of not only specialty choice, but also which physicians care for Medicaid and uninsured populations. Some studies also suggest that race/ethnicity is a stronger predictor of this outcome than a physician's socioeconomic status, National Health Service Corps membership, or International Medical Graduate status. ${ }^{4-6}$ In addition, one estimate predicts that a broad ban on race-based affirmative action could lower the percentage of underrepresented minorities (URM, defined by the study as Black, Latino, or Native American) in medical school by $70 \%{ }^{7}$ These research findings link affirmative action directly to disparities in primary care access and suggest that any practical policy approach to the US healthcare workforce should account for the racial representation of physicians-in-training.

To explore these connections, we assessed the potential effect of a broad affirmative action ban on primary care provision to patients with Medicaid or no health insurance. More specifically, we estimated how different racial proportions within incoming medical school classes across the nation might affect the number of new PCPs caring for low-income populations over the next decade. Assuming 4 years of medical school and 3 years of residency training, we focused on incoming medical school students from 2016-2018, who would potentially be in primary care practice by 2025 .

We used a previously published projection of URM medical student proportions under a broad affirmative action ban. This 2003 study simulated medical schools admitting URM applicants at the same rate as white applicants with similar GPA and MCAT scores and then tabulated the number of students admitted from each racial group under the simulation. ${ }^{7}$ We defined practicing primary care physicians as new internal medicine, pediatrics, family medicine, and medicine-pediatrics residency graduates who do not enter subspecialty training, according to data from the Accreditation Council of Graduate Medical Education (ACGME) ${ }^{8}$ Then, we determined the proportion of primary care 
residency graduates likely to care for patients with Medicaid and patients without insurance. For each scenario, we calculated the probability of a matriculating medical student practicing primary care with a Medicaid or uninsured patient panel. More specifically, we multiplied the probability of serving as a PCP with Medicaid or uninsured patients by the racial/ethnic distribution of medical students in the scenario.

Overall, previously published data confirm that AfricanAmerican and Latino physicians are much more likely to enter primary care and work with lower-income patients with Medicaid or no insurance (see Table 1). ${ }^{5,6,8}$ Based on these statistics, Figure 1 summarizes our estimates of the number of future PCPs caring for these populations that would enter medical school from 2016-2018 under three scenarios: the status quo, ${ }^{9}$ an affirmative action ban, ${ }^{7}$ and a "racial parity" scenario, in which the racial/ethnic composition of the nation's 21,000 annual allopathic medical school enrollees ${ }^{9}$ matched that of the general population. ${ }^{10}$

We calculate that an affirmative action ban in medical schools would create approximately 361 fewer PCPs who care for Medicaid and uninsured patients compared to current conditions - a $14 \%$ decrease from the status quo. Using the federal government's ratio of one primary care physician to 3500 people as the threshold for defining a primary care health

Table 1 Specialty Choice and Likelihood of Working with Medicaid and Uninsured Patients by Physician Race/Ethnicity

\begin{tabular}{lllll}
\hline \hline Outcome/scenario & White & $\begin{array}{l}\text { Asian/ } \\
\text { Pacific } \\
\text { Islander }\end{array}$ & Latino & $\begin{array}{c}\text { African- } \\
\text { American }\end{array}$ \\
\hline $\begin{array}{l}\text { (1) Proportion of } \\
\text { medical students } \\
\text { entering primary care } \\
\text { residency fields: } \\
\text { Internal Medicine, }\end{array}$ & 0.429 & 0.584 & 0.549 & 0.548 \\
$\begin{array}{l}\text { Pediatrics, Family } \\
\text { Medicine, or }\end{array}$ & & & & \\
$\begin{array}{l}\text { Medicine-Pediatrics } \\
\text { (2) Proportion of final } \\
\text { residents in primary } \\
\text { care programs NOT } \\
\text { entering subspecialist } \\
\text { training }\end{array}$ & 0.489 & 0.398 & 0.502 & 0.578 \\
$\begin{array}{l}\text { (3) Percentage of patients } \\
\text { with Medicaid or no } \\
\text { health insurance, by } \\
\text { race/ethnicity of } \\
\text { physician }\end{array}$ & 0.125 & 0.208 & 0.281 & 0.264 \\
$\begin{array}{l}\text { (4) Overall probability } \\
\text { of an incoming } \\
\text { medical student } \\
\text { becoming a PCP to }\end{array}$ & $\mathbf{0 . 0 2 6 1}$ & $\mathbf{0 . 0 4 8 3}$ & $\mathbf{0 . 0 7 7 3}$ & $\mathbf{0 . 0 8 3 7}$ \\
$\begin{array}{l}\text { Medicaid and } \\
\text { uninsured patients }\end{array}$ & & & & \\
\hline
\end{tabular}

Notes: Row (1) shows the proportion of medical students entering primary care residency fields, by racelethnicity based on 2011-2014 data from the ACGME. Row (2) shows the proportion of $3 \mathrm{rd}$ year residents in these fields who did not enter subspecialist fellowship after residency. Row (3) shows the sum of the percentage of Medicaid patients plus the percentage of uninsured patients being cared for physicians of different races based on an analysis of the 2010 Medical Expenditure Survey (Marrast 2013); our calculation assumes that this proportion is roughly equivalent to the likelihood that a physician of a given race practices in a safety net setting

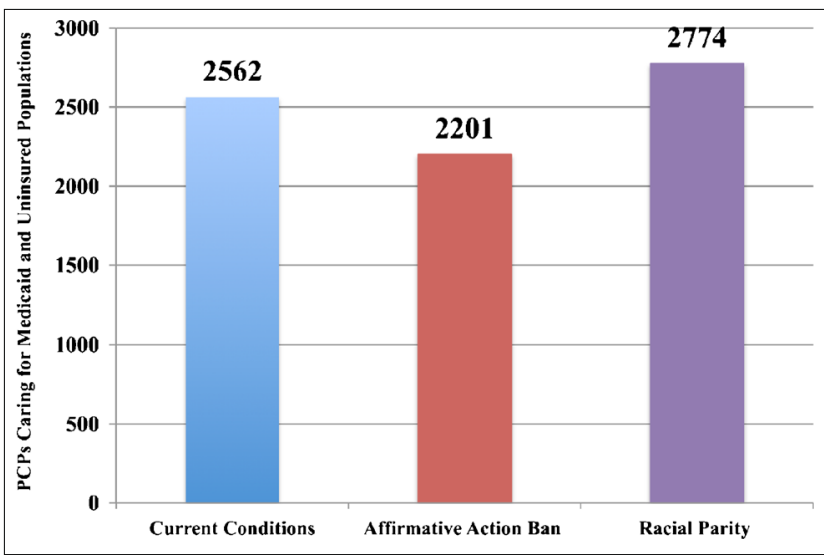

\begin{tabular}{|c|c|c|c|}
\hline \multicolumn{4}{|c|}{ Proportions of Incoming Medical Students by Race/Ethnicity, Under Each Scenario } \\
\hline $\begin{array}{c}\text { African- } \\
\text { American }\end{array}$ & $7.7 \%$ & $2.3 \%$ & $12.9 \%$ \\
\hline $\begin{array}{c}\text { Asian/Pacific } \\
\text { Islander }\end{array}$ & $22.5 \%$ & $25.9 \%$ & $5.5 \%$ \\
\hline Latino & $9.7 \%$ & $2.9 \%$ & $17.4 \%$ \\
\hline White & $60.1 \%$ & $69.2 \%$ & $63.9 \%$ \\
\hline
\end{tabular}

Notes: Data for 'Current Conditions' scenario taken from AAMC FACTS Database. 'Affirmative Action Ban' scenario assumes $70 \%$ lower Latino and African-American enrollment (Cohen 2003). 'Racial Parity' data reflects U.S. race/ethnicity proportions from 2014 U.S. Census data. AAMC does not consider Asian/Pacific Islanders as underrepresented in medicine. Though Native Americans are considered underrepresented by the AAMC, complete ethnicity in the AAMC data, which includes both African-Americans and Africans, so we cannot distinguish" between those groups here.

Figure 1. New Primary Care Physicians Caring for Medicaid and Uninsured Patients by 2025, Under Alternative Workforce Scenarios.

professional shortage area, ${ }^{3}$ this indicates that an affirmative action ban could deny primary care to over 1.25 million lowincome Americans. Put differently, a ban would deny primary care access to a population the size of Colorado's entire Medicaid program (and larger than the Medicaid populations in two-thirds of US states). In the 'racial parity' scenario, in contrast, admitting a 3-year cohort of medical students representative of the US's racial and ethnic diversity could provide a primary care workforce capable of caring for 739,000 more low-income Americans compared to the status quo.

Limitations of these data sources and, by extension, of our results include the lack of ACGME data regarding graduating residents who neither go into fellowship nor primary care practice and the considerable uncertainty about what constitutes an appropriate ratio of primary care physicians to patients, particularly as practice patterns and new systems of care develop. ${ }^{11}$

Another concern is that California, Texas, Florida, and several other states have already enacted affirmative action bans. However, the three largest states with a ban enacted their policies years before the data subject to this analysis existed, meaning that our results already factor in the existence of these state bans. ${ }^{7,12}$ In addition, the fact that the Supreme Court chose to hear Fisher v. University of Texas at Austin despite Texas's affirmative action ban speaks to the federal government's fundamentally different authority as compared to state legislatures and circuit courts - and the possibility of an even more stringent ban in the future than those 
currently in effect in some states. While these limitations may make our overall estimates more uncertain, they are unlikely to reverse the central finding of our analysis - namely, that a more diverse workforce is more likely to care for vulnerable populations in primary care settings than is a less diverse workforce.

Thus, we find that an affirmative action ban would likely exacerbate barriers to primary care in communities with the greatest need at a time when expansion is most necessary. As the prevalence of chronic diseases grows and millions of Americans are insured under the Affordable Care Act, unmet needs for primary care will increase. The likely impact of an affirmative action ban is therefore a worsening of healthcare disparities related to income, geography, and race/ethnicity and thus a setback for one of the Surgeon General's stated priorities. ${ }^{13}$

Medical school admission remains a very competitive process: from 2013-2014 through 2015-2016, only $36 \%$ of African American applicants and $42 \%$ of all applicants were offered admission. ${ }^{9}$ This fierce competition gives admissions committees the luxury of selectivity and empowers them to configure each class in accordance with their priorities. These factors - selectivity and flexibility - leave medical school admissions committees well positioned to increase the future safety net workforce, if they have the tools and commitment to do so. Medical school admission, after all, is the initial decision point that most strongly influences the future of the healthcare workforce. In contrast, the residency match process is often too late in training to substantially shape most trainees' clinical interests, since most fourth-year medical students have already chosen whether or not they will practice primary care. Moreover, residency selection can only operate on the mix of students already admitted to medical school. An affirmative action ban considerably hampers the selectivity and flexibility medical schools currently enjoy and would likely worsen access to primary care among low-income populations for years to come.

We also contend that race-blind admissions are fundamentally at odds with the goals of medical education. First, racial and ethnic diversity among medical students enhances the ease and increases the confidence with which non-URM medical students engage with diverse patient populations. ${ }^{14,15}$ Growing more comfortable engaging with people of different backgrounds might encourage more non-minority medical students to serve Medicaid and uninsured patient populations. While some have suggested that a sense of professionalism alone should encourage physicians to care for Medicaid patients, regardless of race, evidence to date suggests that this ethic on its own has been inadequate. ${ }^{16}$

Second, as the AAMC's mission statement declares, medical schools are charged with supplying the nation with new physicians "to improve the health of all." Arguably, this mission justifies the substantial public investment in physician training, with examples including state-funded medical schools with heavily subsidized tuition and federal funds for graduate medical education. The role of the nation's medical schools should be seen in this light - a duty to train the physician workforce of tomorrow that meets our society's needs rather than an obligation to bestow the benefits of the profession upon any individual applicant. With this social commitment in mind, it follows naturally that policymakers should favor a diverse workforce more willing to care for our society's most medically needy members.

Some policy analysts, including the Institute of Medicine's Board on Health Sciences Policy, argue that increased diversity in medical students is a compelling national interest. ${ }^{17}$ The preceding analysis may provide empirical evidence suggesting that affirmative action in medical school admissions serves that compelling interest. While the Supreme Court for now has supported the ongoing right of universities to use affirmative action, future legal challenges - or new state laws - may produce the opposite result. In that case, what policy options exist that might mitigate a ban's pernicious effects? Three states (Missouri, Arkansas, and Kansas) recently enacted laws licensing new medical school graduates to practice in underserved areas without residency training; however, to date, no graduates have entered the program, and the implications of this plan for quality of care are unclear. University of California medical schools, which operate under California's statewide affirmative action ban, have developed Programs in Medical Education (UCPRIME) to enroll applicants with a proven interest in caring for low-income or otherwise disadvantaged populations. Programs like UCPRIME might reduce the ban's negative impact, and it is worth noting that a high percentage of programs' graduates have been URM students. ${ }^{18}$ Moving forward, policymakers concerned with these issues would benefit from future research further examining which medical schools have been particularly successful at producing primary care physicians who care for Medicaid and uninsured patients.

Other approaches may involve greater numbers of international medical graduates or expanding the scope of practice for nurse practitioners (NPs) and physician assistants (PAs) - though entry into primary care fields among NPs and PAs has also declined in recent years. ${ }^{19}$ These options also raise the question of whether a more racially diverse workforce in other healthcare professions similarly would increase access to primary care for Medicaid and uninsured populations.

Ultimately, medical student diversity and primary care access for underserved communities are inextricably linked. Quantifying this relationship highlights the importance of medical school admissions policy. If we intend to address the US's current shortage of access to primary care, particularly in low-income neighborhoods and rural areas, we should consider supporting policies that tether diversity concerns with one of our profession's unquestionable ethical priorities - access to care for all populations. This relationship also strongly suggests that the medical community - and the broader health policy community — have a major stake in affirmative 
action policies nationwide, whose fate may well determine the ability of the healthcare workforce to care for the nation's neediest populations for decades to come.

Acknowledgments: We would like to thank University of California Program in Medical Education (UCPRIME) and especially Dr. Leigh Kimberg, MD, for granting us access to the UCPRIME program data. We would also like to thank Prof. Meredith Rosenthal, PhD, and Dr. Elisabeth Wilson, MD, MPH, for reviewing this article before submission.

Corresponding Author: Michael O. Mensah, B.A.; Department of Health Policy \& Management, Harvard School of Public Health / University of California, San Francisco, 677 Huntington Ave, Room 406, Boston, MA 02115, USA (e-mail: mim159@mail.harvard.edu).

\section{Compliance with ethical standards:}

Conflicts of Interest: Michael Mensah is a member of UCSF PRIME Matriculating Class of 2012. The authors have no other conflicts of interest.

\section{REFERENCES}

1. Decker SL. Two-thirds of primary care physicians accepted new medicaid patients in 2011-12: a baseline to measure future acceptance rates. Health Aff. 2013;32(7):1183-1187.

2. Institute of Medicine. Graduate Medical Education that meets the Nation's Health needs. Washington, DC: The National Academies Press; 2014.

3. Bureau of Health Workforce, HRSA, US Department of Health \& Human Services. Designated Health Professional Shortage Areas Statistics 2016: Basic Primary Medical Care Preformatted Report: Table 1. Pg. 3. Available at: https://datawarehouse.hrsa.gov/tools/hdwreports/Reports. aspx. Accessed June 9, 2016

4. Saha S, Shipman SA. Race-neutral versus race-conscious workforce policy to improve access to care. Health Aff. 2008;27(1):234-245.

5. Marrast LM, Zallman L, Woolhandler, S, Bor DH, McCormick D. Minority Physicians' Role in the Care of Underserved Patients: Diversifying the Physician Workforce May Be Key in Addressing Health Disparities. JAMA Int Med. 2013;E1-E3.
6. Komaromy $\mathbf{M}$, Grumbach $\mathbf{K}$, Drake $\mathbf{M}$, et al. The role of black and Hispanic physicians in providing health care for underserved populations. N Engl J Med. 1996;334(20):1305-1310.

7. Cohen JJ. The consequences of premature abandonment of affirmative action in medical school admissions. JAMA. 2003;289:1143-9.

8. ACGME Department of Applications and Data Analysis. ACGME Data Resource Books 2011-14. ACGME Data Resource. Accreditation Council for Graduate Medical Education, 2014. Available at: http://www.acgme. org/About-Us/Publications-and-Resources/Graduate-Medical-EducationData-Resource-Book. Accessed June 9, 2016

9. American Association of Medical Colleges. FACTS: Applicants, Matriculants, Enrollment, Graduates, M.D.-Ph.D., and Residency Applicants Data. In: AAMC, 2016. Available at: https://www.aamc.org/data/facts. Accessed June 9, 2016.

10. United States Census Bureau. 2014 American Community Survey 1-Year Estimate. US Census Bureau; 2014. Available at: http://www.census.gov/ programs-surveys/acs/technical-documentation/table-and-geographychanges/2014/1-year.html. Accessed June 9, 2016.

11. Green LV, Savin S, Lu Y. Primary Care Physician Shortages Could Be Eliminated Through Use of Teams, Nonphysicians, and Electronic Communication. Health Aff. 2013;32(1):11-19.

12. National Council of State Legislators. Affirmative Action: State Action. Apr. 2014. Web. Available at: http://www.ncsl.org/research/education/ affirmative-action-state-action.aspx. Accessed June 9, 2016.

13. US Surgeon General Vivek Murthy. Elimination of Health Disparities. Surgeongeneral.gov. Health and Human Services. Available at: http://www. surgeongeneral.gov/priorities/prevention/strategy/elimination-of-healthdisparities.html. Accessed June 9, 2016.

14. American Association of Medical Colleges.. Altering the Course: Black Males in Medicine. Washington DC: AAMC; 2015. Available at: https:// members.aamc.org/eweb/upload/Black_Males_in_Medicine_Report_ WEB.pdf. Accessed June 9, 2016.

15. Saha S, Guiton G, Wimmers PF, Wilkerson L. Student Body Racial and Ethnic Composition and Diversity-related Outcomes in US Medical Schools. JAMA. 2008;300(10):1135-1145.

16. Casalino LP. Professionalism and Caring for Medicaid Patients-the $5 \%$ Commitment? N Engl J Med. 2013;369(19):1775-1777.

17. Institute of Medicine. In the Nation's Compelling Interest: Ensuring Diversity in the Health-care Workforce. Washington, DC: The National Academies Press; 2004.

18. University of California Program In Medical Education. "UC PRIME Enrollment" UC PRIME. 2015. Accessed June 9, 2016.

19. Petterson, SM, Phillips, RL, Bazemore, AW, Burke, BT, Koinis, GT. Relying on NPs and PAs Does Not Avoid the Need for Policy Solutions for Primary Care. Publication and Reports. Available at: http://www.aafp.org/ afp/2013/0815/p230.html. Accessed June 9, 2016. 